\title{
ANÁLISE DA PREFERÊNCIA DO ESTILO DE APRENDIZAGEM DOS ALUNOS DE GRADUAÇÃO EM CIÊNCIAS CONTÁBEIS
}

\author{
ANALYSIS OF LEARNING STYLE PREFERENCE OF GRADUATE STUDENTS IN \\ ACCOUNTING
}

Salete Turra

sallete.turra@gmail.com

Universidade Regional de Blumenal
Fellipe Andre Jacomossi

xfellipe@gmail.com

Universidade Regional de Blumenal

\author{
Vania Tanira Biavatt \\ vaniabiavatti@hprada.com.br \\ Universidade Regional de Blumenal
}

\begin{abstract}
RESUMO: Os estilos de aprendizagem vêm sendo cada vez mais estudados e desenvolvidos no ensino superior, pois possibilitam ao aluno identificar novas formas de pensar sobre seu próprio estilo. O objetivo da pesquisa foi analisar a preferência em relação ao estilo de aprendizagem, demonstrada pelos alunos do curso de Ciências Contábeis matriculados na UCEFF Faculdades, no município de Chapecó/SC. As informações foram coletadas por meio do questionário de estilos de aprendizagem de Kolb (1984) e analisadas de forma descritiva, bem como, quantitativa. A população da pesquisa compreende todos os cursos de graduação em Ciências Contábeis do município de Chapecó/SC. Para a escolha da amostra utilizou-se o método não probabilístico por conveniência. Deste modo, a amostra compreende uma faculdade de graduação em Ciências Contábeis do município de Chapecó/SC, qual seja a faculdade UCEFF. O questionário foi enviado por meio eletrônico, para um total de 150 alunos matriculados no curso de Ciências Contábeis da instituição em análise, sendo a amostra final composta por 53 alunos respondentes. Os resultados demonstram que o estilo de aprendizagem predominante nos estudantes do curso de Ciências Contábeis da UCEFF Faculdades foi o divergente.
\end{abstract}

Palavras-chave: Estilo de Aprendizagem. Inventário de Kolb. Ciências Contábeis.

ABSTRACT: Learning styles have been increasingly studied and developed in higher education, as they allow the student to identify new ways of thinking about their own style. The objective of the research was to analyze the preference in relation to the learning style, demonstrated by the students of Accounting enrolled in UCEFF University, in Chapecó/SC. Information was collected through a questionnaire learning styles of Kolb (1984) and analyzed descriptively and qualitatively. The study population includes all graduate courses in Accounting from Chapecó/SC. For choosing the sample we used non-probabilistic method for convenience. Thus, the sample comprises a University degree in Accounting from Chapecó/SC, which is the UCEFF University. The questionnaire was sent electronically, for a total of 150 students enrolled in the Accounting course of UCEFF and the final sample consisted of 53 respondents students. The results show that the predominant style of learning in students was divergent.

Keywords: Learning Style. Kolb Learning Style Inventory. Accounting. 


\section{INTRODUÇÃO}

Com a constante evolução do conhecimento, o ensino da contabilidade necessita de modelos onde os alunos possam participar do método de ensino aprendizagem, possibilitando a interação do conhecimento entre professor e aluno. Além disso, espera-se que o processo de ensino da contabilidade apresente uma nova percepção de ação lógica e crítica, possibilitando ao aluno novas formas de pensar sobre seu próprio estilo, cultural e profissional (SILVA, 2006).

O processo de aprendizagem tem como objetivo o alcance do conhecimento que é adquirido por meio de caminhos diferentes para cada pessoa. Dessa forma, entende-se que estes caminhos são os estilos de aprendizagem propriamente ditos, visto que estes são os meios utilizados para compreender assuntos tratados em aulas, ou seja, é a condição particular do indivíduo para conseguir captar, processar, reter e transformar o conhecimento que lhe fora apresentado. $\mathrm{O}$ estilo de aprendizagem pode ser definido ainda, como a metodologia utilizada para obter-se conhecimento, visto que este não pode ser considerado como o aquilo que se aprende, mas sim, a forma como se age durante o exercício do aprendizado (OLIVEIRA, 2012).

Nesse sentido, para Felder e Spurlin (2005) identificar os estilos de aprendizagem não significa classificar e modificar a cultura dos alunos, mas sim detectar os diferentes pontos fortes e preferencias do indivíduo. Para os autores, também este processo também pode ser considerado um meio de avaliação da atitude dos alunos no processo de informação. Os estudantes podem ter habilidades associadas a várias categorias de cada aspecto do estilo de aprendizagem, que precisam ser definidas e postas em prática em suas habilidades preferidas. A teoria de estilos de aprendizagem vem sendo estudada e desenvolvida há anos no ensino superior. Há relatos das contribuições desta para a evolução do ensino e espera-se que muitos estudos ainda venham a contribuir (FIGUEIREDO; NORONHA; OLIVEIRA, 2008).

Nesse contexto, diversas foram às pesquisas realizadas que analisaram a preferência dos estilos de aprendizagem de alunos de graduação em Ciências Contábeis, tanto em âmbito nacional como internacional. Dentre estas pesquisas, pode-se elencar os estudos desenvolvidos por Baldwin (1984), Stout (1991), Leite, Batista, Paulo e Siqueira (2008), Valente, Abib e Kunsnik (2009) e Reis, Paton e Nogueira (2012). No âmbito de outras disciplinas, como gerenciamento financeiro, destaca-se a pesquisa de Fox e Bartoholomae (1999), em vários cursos e várias universidades, o estudo de Cerqueira (2000), e ainda, em outros contextos, os estudos de Joy e Kolb (2009) e Manolis, Burns, Assudani e Chinta (2013). Entretanto, estas pesquisas indicam que há uma lacuna entre as preferências dos estilos de aprendizagem dos alunos, sendo que as evidências apresentadas nestes estudos anteriores demonstram a relevância de pesquisas neste sentido, no sentido de contribuir para com o ensino superior em Ciências Contábeis.

Diante desse contexto, esta pesquisa pretende responder a seguinte questão problema: qual é a preferência de estilo de aprendizagem dos alunos do curso de Ciências Contábeis? Desta forma, o objetivo do estudo foi analisar a preferência em relação ao estilo de aprendizagem demonstrado pelos alunos do curso de Ciências Contábeis matriculados na UCEFF Faculdades, no município de Chapecó/SC.

O estudo justifica-se por fornecer informações sobre os diferentes estilos de aprendizagem dos alunos do curso de Ciências Contábeis, contribuindo para a identificação de seus próprios estilos e para capacitação dos professores quanto ao material e recursos adequados a serem utilizados em suas aulas, para que assim, atendam aos estilos de aprendizagem específicos dos alunos. Cada vez mais se faz importante reconhecer e mensurar as diferenças de cada pessoa, 
de tal modo a conseguir identificar as características de cada indivíduo, com a intenção de conferir um bom desempenho. A partir da identificação das características dos indivíduos, podem-se estabelecer ainda, prognósticos relacionados à conduta futura das pessoas, conseguindo identificar-se as qualidades de cada uma em estudos e planos educativos (CERQUEIRA, 2000).

Do mesmo modo, Leite, Batista, Paulo e Siqueira (2008) comentam que os diferentes estilos de aprendizagem favorecem informações acerca do estudante universitário, com o intuito de se conhecer como o mesmo aprende, possibilitando uma maior satisfação e aproveitamento em seus estudos. Além disso, os autores destacam que deveria ser responsabilidade dos programas de ensino empregar métodos de avaliação que diagnosticassem os diferentes estilos de aprendizagem, para assim, obter novas metodologias de ensino, aprendizagem e avaliação apropriadas às expectativas dos alunos.

A pesquisa justifica-se ainda, pela escolha da Faculdade UCEFF, que se deu pelo fato desta instituição ser a maior faculdade do oeste de Santa Catarina, que tem como intuito, conforme a Lei das Diretrizes e Bases da educação nacional - LDB (Lei 9.394/96), em seu Art. 43, §II, "formar diplomados nas diferentes áreas de conhecimento, aptos para inserção em setores profissionais e para a participação no desenvolvimento da sociedade brasileira, e colaborar na sua formação contínua”.

\section{REFERÊNCIAL TEÓRICO}

Neste tópico aborda-se a revisão de literatura. Inicialmente apresenta-se a conceituação dos estilos de aprendizagem, segue-se com a abordagem sobre os estilos de aprendizagem de Kolb e por fim trata-se a respeito dos estudos relacionados à temática proposta.

\subsection{Estilos de Aprendizagem}

A compreensão da aprendizagem deu-se em todas as áreas do conhecimento direcionada ao processo que desenvolveu técnicas de como compilar, gravar e recuperar as informações (CERQUEIRA, 2000). Diversos trabalhos pesquisaram o conhecimento e as novas tecnologias no ensino e na aprendizagem, que consequentemente produziram os processos da aprendizagem e na mesma sucessão seus estilos. Os estudos relacionados aos estilos de aprendizagem vêm sendo realizados na área da educação, dada sua importância por possibilitar ao estudante que este se conscientize da sua preferência quanto aos estilos, possibilitando uma melhor compreensão e absorção do aprendizado (FIGUEIREDO; NORONHA; OLIVEIRA, 2008; SANTOS; MOGNON, 2010).

O aluno deve buscar novos conhecimentos, ampliando assim seus saberes, porém o processo de construção diferenciada do aprendizado depende muitas vezes do seu estilo particular de aprender. Este processo pode ser entendido quando são observadas crianças que aprendem a dizer e juntar as palavras após lerem livros de alfabetização, enquanto outros aprendem brincando com peças que contenham letras (PORTILHO, 2011; REIS; PATON; NOGUEIRA, 2012).

Elementos como personalidade, história de vida, cultura, motivação e fatores ambientais modificam o entendimento que o indivíduo faz da realidade, influenciam nos processos de aprendizagem e caracterizam uma maneira particular de aprender. A prática de aprender é uma atividade muitas vezes dificultosa que precisa ser realizada em diferentes âmbitos, como individual e social. O processo de aprendizagem depende da motivação e 
interesse do indivíduo bem como da qualidade entre aprender e adquirir o conhecimento (SIQUEIRA; PRATES; PAULA, 2012).

Os estilos de aprendizagem são considerados importantes em todas as áreas do conhecimento, pois permitem constituir um processo educacional eficaz, sendo consideradas, portanto, um modelo crítico no processo de ensino e aprendizagem. Isso se deve à necessidade dos educadores em aperfeiçoar o ensino empregando técnicas para compreender os estilos de aprendizagem dos alunos, e assim, melhorar o método educacional (VALENTE; ABIB; KUSNIK, 2009).

Apesar de não haver um conceito definido entre os autores que estudaram os estilos de aprendizagem, várias são as teorias que pesquisaram como as pessoas aprendem, objetivando desta forma inventariar os estilos de aprendizagem (REIS; PATON; NOGUEIRA, 2012). Deste modo, a pesquisa apresenta definições de diversos autores nacionais e internacionais, conforme se apresenta no Quadro 1:

Quadro 1 - Definições de Estilos de Aprendizagem

\begin{tabular}{|c|c|}
\hline Autores & Conceito \\
\hline Kolb (1984) & $\begin{array}{l}\text { Estado contínuo, ocorrido devido às características } \\
\text { que se origina das combinações de conhecimento entre } \\
\text { o indivíduo e seu ambiente. }\end{array}$ \\
\hline Felde; Silverman (1988) & $\begin{array}{l}\text { Capacidade de adaptar ao seu estilo ou a sua } \\
\text { preparação prévia de aprendizagem. Os alunos } \\
\text { aprendem de várias formas: ver e ouvir; refletir e agir; } \\
\text { raciocinar; memorizar, visualizar e também por meio } \\
\text { de analogias matemáticas, como desenhos. }\end{array}$ \\
\hline Allessandrini et. al. (1999) & $\begin{array}{l}\text { Estilo próprio, exclusivo utilizado para falar, escrever, } \\
\text { assumir uma opinião própria de tal modo a adquirir a } \\
\text { marca do sujeito. }\end{array}$ \\
\hline Cerqueira (2000) & $\begin{array}{l}\text { São as interações de diversos fatores como: } \\
\text { hereditários, experienciais, exigências do ambiente. }\end{array}$ \\
\hline Silva (2006) & $\begin{array}{l}\text { Forma particular de adquirir habilidades por meio da } \\
\text { experiência ou anos de estudo e da adaptação à busca } \\
\text { do ambiente. }\end{array}$ \\
\hline Figueiredo; Noronha; Oliveira (2008) & $\begin{array}{l}\text { Procura de meios para facilitar a aprendizagem, } \\
\text { considerando a dificuldade do processo de inclusão de } \\
\text { novas tecnologias presentes no cotidiano. }\end{array}$ \\
\hline Portilho (2011) & $\begin{array}{l}\text { O procedimento de como o aluno gosta de atingir suas } \\
\text { tarefas, ou seja, diferentes costumes de usar a } \\
\text { inteligência. }\end{array}$ \\
\hline Oliveira (2012) & $\begin{array}{l}\text { Método pessoal do indivíduo para aprender conforme } \\
\text { o seu modo, e conforme as diferentes circunstâncias } \\
\text { de trabalho. }\end{array}$ \\
\hline Williams; Brown; Etherington (2013) & $\begin{array}{l}\text { É o modo como os indivíduos escolhem para } \\
\text { processar as novas informações e aplicar para o seu } \\
\text { aprendizado ideal. }\end{array}$ \\
\hline
\end{tabular}

Fonte: dados da pesquisa.

Por meio do Quadro 1, compreende-se que cada autor relaciona os estilos de aprendizagem a certas características, tais como ambientais, sociais, culturais, comportamentais, de costumes, memorísticas e utilitárias, demonstrando a maneira como o indivíduo se comporta no processo de aprendizagem. Portanto, a compreensão sobre os diferentes estilos de aprendizagem é muito importante para o aluno, uma vez que avaliada à maneira como o conhecimento é entendido, este pode utilizar-se destes métodos para 
aperfeiçoar seu próprio estilo de aprender, buscando uma melhor capacidade para desenvolver seu conhecimento (OLIVEIRA, 2012).

\subsection{Estilo de Aprendizagem de Kolb}

$\mathrm{O}$ autor David Kolb iniciou suas pesquisas a respeito dos estilos de aprendizagem em 1971, em uma linha de estudos aplicados com estudantes universitários, devido à percepção da necessidade de associar o ato de aprender com as experiências e o ambiente. "Porém, essas ideias, consideradas tão importantes como são as capacidades de aprender, parecem limitadas ou sujeitas a máximas como: colocar maior empenho ou esforço por parte do estudante”. Em vista disto, Kolb elaborou um modelo experiencial no qual compreende o processo de aprendizagem baseado na própria experiência (OLIVEIRA, 2012; CERQUEIRA, 2000, p. 48).

Neste contexto, Kolb (1984) em sua teoria experimental destaca que a conquista proporcionada pelo desenvolvimento do aluno esta subordinada à aprendizagem, deste modo, percebeu a necessidade de criar o inventário de estilos de aprendizagem. Inicialmente este inventário apresentava nove componentes, já em 1984, devido as constantes mudanças na capacidade de examinar novas oportunidades e aprender com erros, passou a ter doze sentenças. No Inventário de Kolb as sentenças apresentam quatro opções, dispostas de forma horizontal, sendo assim os alunos ordenam as opções de cada sentença e classificando-as de 1 (menos representa o aluno) a 4 (melhor descreve o aluno), conforme a menor ou maior identificação pessoal do indivíduo com cada opção apresentada. Com os pesos das respostas, são calculados os índices para identificar o melhor estilo de aprendizagem de cada amostra (OLIVEIRA, 2012; CERQUEIRA, 2000).

Na concepção de Leite, Batista, Paulo e Siqueira (2008) o Inventário de Kolb, é constituído de algumas decisões associadas às alternativas. Estas recebem um peso conforme o que o estudante acredita que melhor descreva suas atitudes e sensações no momento em que se está aprendendo.

O modelo de Kolb apresenta um quadrante cíclico que classifica os quatro modos de aprendizagem circulares de um indivíduo, dos quais são considerados como: acomodador, divergentes, assimiladores e convergente. Estes modos por sua vez, são dimensionados por meio de quatro índices a partir dos pesos que o estudante atribuiu (WILLIAMS, BROWN; ETHERINGTON, 2013).

$\mathrm{O}$ índice concrete experience (experiência concreta) é conceituado como aprender pelo uso de sentimentos e experiências. Os indivíduos deste estilo se identificam por meio de exemplos nos quais se sintam envolvidos, gostam de trabalhar em grupo; reflexive observation (observação e reflexão) definida como a aprendizagem por meio da observação. Os indivíduos deste estilo aprendem por meio do julgamento, reflexão, observação e assistindo aulas; abstract conceptualization (conceituação abstrata) aprendizagem conhecida como o uso de ideias, lógica, está baseado no pensamento e raciocínio lógico. Aprendem por meio de professores, teorias e conceitos; active experimentation (experiência ativa) conhecida como a aprendizagem do fazer, os alunos deste estilo realizam atividades práticas, projetos e gostam de fazer tarefas em casa (CERQUEIRA, 2000). Deste modo, o ciclo de aprendizagem de Kolb (1984) é apresentado na Figura 1:

Figura 1- Ciclo de aprendizagem de Kolb 


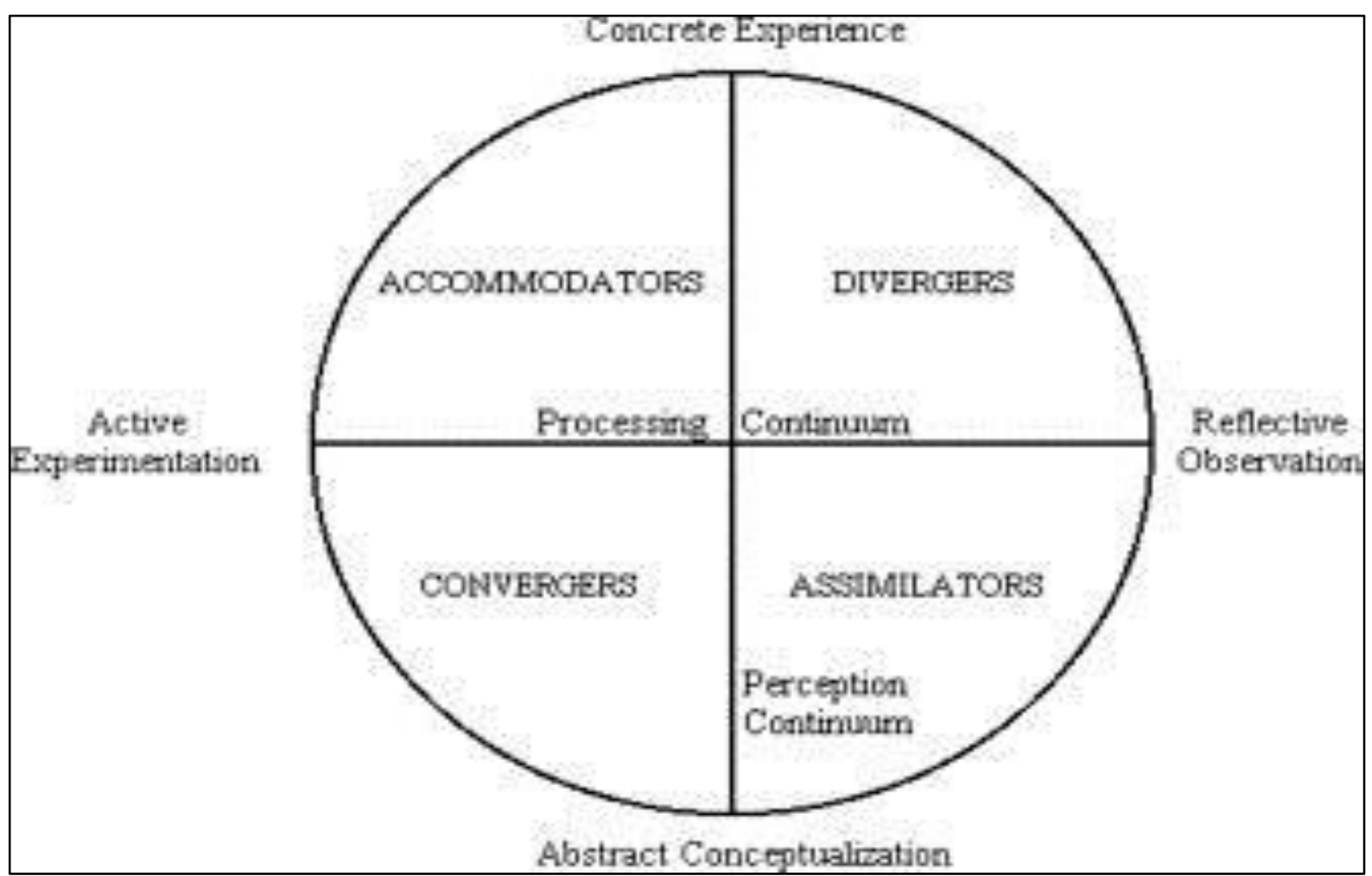

Fonte: Kolb (1984).

O modelo de Kolb estabelece que toda aprendizagem requer um movimento cíclico de quatro estilos, no qual cada indivíduo se caracteriza em um dos estilos fundamentados, estes estão no alcance de duas dimensões: processamento e percepção (SILVA, 2006).

Para Oliveira (2012) o estilo accommodators (acomodador), pode ser definido como processo de aprendizagem no qual o indivíduo aprende baseado em sentir e fazer. Alunos com este perfil buscam fazer, realizar planos e experimentos, confiando em seu conhecimento e em sua intuição. Já para Cerqueira (2000) os acomodadores têm como preferencias a experimentação ativa e a experiência concreta. Devido ao gosto da experimentação aprendem inventando coisas, aceitando desafios em circunstâncias imediatas, agindo pelo sentir ao invés da lógica. Na visão de Williams, Brown e Etherington (2013, p. 111) os "acomodadores desfrutam de experiência prática e prosperam em situações novas e desafiadoras".

Identificam-se com o estilo assimilators (assimilador), os indivíduos que compreendem diferentes informações, classificando-as, em uma ordem lógica. Aprendem essencialmente pela observação que induz a reflexão e pela conceituação imaterial, criam habilidades cuja preocupação não é usar a teoria e sim o raciocínio para inventar modelos pensativos e teóricos. Usam a lógica, de que os valores da prática são mais ativos as ideias do que as pessoas (WILLIAMS; BROWN; ETHERINGTON, 2013; CERQUEIRA, 2000). Para Silva (2006) o estilo assimilador é conceituado como a preferência que o aluno tem para habilidades lógicas, estes aprendem mais por observações e utilizam o raciocino indutivo.

Os alunos com o perfil convergers (convergente) preferem aplicar métodos voltados a prática para executar as tarefas, principalmente quando os exercícios apresentam apenas uma resposta. Almejam a conceituação abstrata e a experimentação ativa, resolvem bem os problemas e assumem as decisões. Atuam melhor nas situações em que existe uma única solução correta, utilizam do raciocínio dedutivo (WILLIAMS, BROWN; ETHERINGTON, 2013; CERQUEIRA, 2000).

Os indivíduos divergers (divergentes) escolhem as circunstâncias conforme o número 
de diferentes expectativas. Atuam bem nas situações que pedem novas ideias, tem o perfil de aprender pela experiência concreta e observação reflexiva. Deste modo, são criativos, distinguem os problemas e compreendem as pessoas (WILLIAMS; BROWN; ETHERINGTON, 2013; CERQUEIRA, 2000).

$\mathrm{O}$ inventário dos estilos de aprendizagem de Kolb pode ser encontrado em diversas pesquisas, o que demonstra a sua importância e comprova a contribuição para a aprendizagem (CERQUEIRA, 2000). Dessa forma, no tópico a seguir tratar-se-á de estudos que utilizaram o instrumento de Kolb em seu embasamento.

\subsection{Estudos Relacionados}

O tema estilos de aprendizagem já foi pesquisado por diferentes autores em contextos nacionais, internacionais e em áreas distintas como saúde, engenharia, educação, contabilidade, entre outas áreas.

Baldwin (1984) utilizou o modelo Kolb de 1976. Em sua pesquisa o autor analisou o melhor estilo de aprendizagem para o desenvolvimento da educação em contabilidade, entre os professores e os alunos. Os achados demonstram que o estilo predominante entre os alunos foi convergente e entre os professores o assimilador. Além disso, os resultados confirmam que os alunos iniciantes aprendem pelos estilos dos professores e que no decorrer do curso passam a identificar seus próprios estilos de aprendizagem.

Stout (1991) em sua pesquisa investigou os estilos de aprendizagem dos estudantes de contabilidade. Foram utilizadas duas metodologias para esta avaliação, sendo um destas o inventário de Kolb de 1984. Não houve diferenças significativas entre os estilos de aprendizagem dos alunos.

Fox e Bartoholomae (1999) avaliaram os estilos de aprendizagem e o desempenho acadêmico de estudantes de uma turma de gerenciamento financeiro, para pesquisar o desempenho. Verificaram a origem, história acadêmica, tempo disponível para se dedicar aos estudos, sexo, idade e raça. Além disso, os estilos de aprendizagem dos alunos foram identificados por meio do inventário de Kolb de 1984. Os resultados demonstram que a história e o tempo dos alunos influenciam nas notas do curso. Quanto aos estilos de aprendizagem a utilização do inventário de Kolb não alcançou resultados significativos na turma de gerenciamento financeiro. Deste modo, o estilo predominante nos estudantes foi o convergente. No que diz respeito ao sexo, os estudantes do sexo masculino se identificam mais com o estilo convergente e acomodador. $\mathrm{O}$ teste não revelou diferenças quanto à idade $\mathrm{e}$ raça, visto que encontraram os mesmos resultados, ou seja, o estilo acomodador.

Cerqueira (2000) aplicou, moldou e validou o Inventário de Estilo de Aprendizagem de Kolb de 1984, com estudantes universitários de vários cursos e de várias universidades brasileiras. Analisou qual a preferência de estilo de aprendizagem dos alunos por área de conhecimento e informação. Além disso, verificou os estilos de aprendizagem por idade, semestre e instituição. Obteve-se como resultados que a predominância entre os alunos foi o estilo assimilador, em todos os semestres e áreas pesquisadas, demonstrando que no decorrer das idades a preferência pelo estilo assimilador diminuía, por outro lado, o estilo de aprendizagem acomodador aumentava. Além disso, observou-se um aumento do estilo convergente nas turmas dos semestres finais.

Os autores Leite, Batista, Paulo e Siqueira (2008) examinaram a relação entre os estilos de aprendizagem e o desempenho acadêmico dos alunos de Ciências Contábeis de uma universidade pública, utilizando como instrumento para coleta dos estilos de aprendizagem o Inventário de Kolb de 1984. Os resultados apontam que o estilo de predominância entre os alunos desta universidade é o divergente. Com relação aos melhores desempenhos, também 
obteve-se o estilo divergente como predominante, todavia, não foi descoberta semelhança entre estilos de aprendizagem e desempenho acadêmico do aluno.

Valente, Abib e Kusnik (2009) identificaram em sua pesquisa, a predominância nos estilos de aprendizagem dos alunos e professores do curso de Ciências Contábeis da Universidade de Ponta Grossa, aplicando o teste de Kolb. Os resultados indicam uma discordância entre a preferência de estilos de aprendizagem dos alunos e o estilo de ensinar dos professores. Os achados indicam que a maioria dos professores prefere ensinar por meio de conceitos, enquanto os alunos preferem aprender por meio de experimentos e descobertas. Deste modo, o estilo de aprendizagem predominante apresentado no estudo foi o convergente.

Joy e Kolb (2009) averiguaram em seu estudo se a cultura influenciava no estilo de aprendizagem dos indivíduos, para tanto, utilizaram o método de Kolb. O questionário foi aplicado em diferentes países, foi considerado à cultura, sexo, idade, nível de escolaridade dos alunos para avaliar os estilos de aprendizagem. Os resultados indicam que o estilo predominante dos alunos foi o assimilador e que a cultura influencia em alguns aspectos os estilos de aprendizagem. Além disso, o estudo divulgou que as pessoas que tem um estilo abstrato são de países mais ricos. Em relação ao sexo, a predominância de estilo foi o convergente seguido pelo assimilador, quanto à faixa etária, destacaram-se os estilos divergente e assimilador.

Reis, Paton e Nogueira (2012) buscaram identificar as diferenças de estilos de aprendizagem dos alunos de graduação em Ciências Contábeis entre universidades públicas e privadas, aplicando o teste de Kolb de 1984. Os resultados indicam o estilo convergente como o de maior influência, enquanto o estilo divergente obteve menor influência nos alunos observados. Já em relação às turmas, estas apresentaram como predominância o estilo acomodador, desta forma, técnicas de aprendizagem foram diferenciadas para cada turma do curso de Ciências Contábeis. Além disso, outro item a ser considerado que pode impactar nos resultados é em relação ao perfil dos alunos do curso de Ciências Contábeis, visto que estes podem exercer atividades específicas na área contábil, e assim, adquirir um perfil de estilo de aprendizagem distinto se comparado com os alunos ingressantes.

Manolis, Burns, Assudani e Chinta (2013) em seu estudo aperfeiçoar o Inventário de Estilo de Aprendizagem de Kolb (1984) tornando-se mais eficaz na identificação do estilo de aprendizagem dos indivíduos, em um nível de medida contínua, transformando-o em um modelo mais econômico e de fácil utilização. A pesquisa teve como aprovação uma validação de multi-amostras que comprovam o emprego desta transformação, proporcionando uma opção adicional de método para o inventário de Kolb. Obteve-se como resultado a aprovação de um método que auxilia a avaliação da eficiência dos estilos de aprendizagem dos alunos e complementa o método de Kolb. Além disso, os resultados sugerem que os quatro índices são válidos, porém pouca evidência é fornecida para confirmar as dimensões do inventário de Kolb.

De acordo com as pesquisas realizadas, pode-se observar que os estudos sobre os estilos de aprendizagem vêm evoluindo ao longo dos anos, principalmente na área contábil, porém, caracterizam-se como necessárias mais pesquisas neste âmbito, dessa forma o presente estudo representa uma contribuição para a literatura.

\section{METODOLOGIA}

A presente pesquisa caracteriza-se quanto aos objetivos como descritiva, pois inventaria e identifica os diferentes os estilos de aprendizagem dos alunos de graduação em Ciências Contábeis. No que tange à abordagem do problema, a pesquisa é classificada como quantitativa. Quanto aos procedimentos adotados para a coleta dos dados, classifica-se como 
pesquisa de levantamento, por meio da aplicação do questionário do Inventário de Estilos de Aprendizagem de Kolb (1984), a todos os alunos matriculados no curso de Ciências Contábeis da UCEFF Faculdades do município de Chapecó/SC. Segundo Kerlinger (1980), a pesquisa de levantamento visa estudar as características de uma determinada amostra, a partir da aplicação de um questionário.

A pesquisa descritiva, expõe as particularidades de uma população ou fenômeno, constituindo relações entre as variáveis estudadas por meio do emprego da coleta de dados (GIL, 2002).

No que tange à abordagem do problema, a pesquisa é classificada como quantitativa, pois conforme Richardson (1999), empregou-se a quantificação tanto nas modalidades de coleta de informações, quanto no tratamento dos dados por meio de técnicas estatísticas. Nesta pesquisa, utilizou-se a análise de frequência e posteriormente à apresentação dos dados em tabelas.

\subsection{População e Amostra de Pesquisa}

A população da pesquisa compreende todos os cursos de graduação em Ciências Contábeis do município de Chapecó/SC. Quanto à escolha da amostra utilizou-se o método não probabilístico por conveniência. Deste modo, a amostra do estudo compreende o curso de graduação em ciências contábeis da UCEFF Faculdades do município de Chapecó/SC. A instituição em questão, apresenta um total de 150 alunos matriculados no curso de Ciências Contábeis, sendo a aplicação do questionário realizada por meio eletrônico, obtendo-se um total de 53 respostas.

As informações foram recolhidas por meio do questionário de inventário de Kolb (1984) e os dados foram coletados no mês de maio de 2014. Os alunos respondentes são de todos os semestres, como a instituição apresenta um processo seletivo anual para o curso de Ciências Contábeis, os semestres representados na pesquisa são: $1^{\circ}, 3^{\circ}, 5^{\circ}$ e $7^{\circ}$.

Após obter-se as respostas dos alunos, procedeu-se a análise dos questionários. Conforme Bardin (1977, p. 42), a análise corresponde a "um conjunto de técnicas de análise das comunicações visando obter, por procedimentos, sistemáticos e objetivos de descrição do conteúdo das mensagens, indicadores (quantitativos ou não) que permitam a inferência de conhecimentos relativos às condições de produção/recepção". Deste modo, o questionário foi composto por doze perguntas, onde foram atribuídos pesos de 1 a 4 pelos respondentes, agrupados e combinados dois a dois. Posteriormente foram lançados no plano cartesiano de Kolb, onde geraram os estilos individuais de aprendizagem dos alunos.

\section{ANÁLISE DOS RESULTADOS}

Após o envio do questionário aos alunos, analisaram-se as informações fornecidas por estes, conforme a teoria de Kolb (1984). A Tabela 1, evidencia os dados demográficos dos alunos da pesquisa.

Tabela 1- Dados demográficos

\begin{tabular}{c|c|c}
\hline Sexo & Alunos & Dados \\
\hline Feminino & 36 & $68 \%$ \\
\hline Masculino & 17 & $32 \%$ \\
\hline Faixa Etária por Idade & Alunos & Dados \\
\hline 16 aos 20 & 31 & $58,49 \%$ \\
\hline 21 aos 23 & 13 & $30,19 \%$ \\
\hline
\end{tabular}

R. Cont. Ufba, Salvador-Ba, v. 9, n. 3, p. 118 - 134, set-dez 2015 


\begin{tabular}{c|c|c}
\hline 24 aos 52 & 9 & $18,87 \%$ \\
\hline Semestre & Alunos & Dados \\
\hline 1 & 14 & $26 \%$ \\
\hline 3 & 21 & $40 \%$ \\
\hline 5 & 8 & $15 \%$ \\
\hline 7 & 10 & $19 \%$ \\
\hline
\end{tabular}

Fonte: dados da pesquisa.

Por meio da Tabela 1, verifica-se, que do total das 53 respostas obtidas, a maior quantidade de respondentes deu-se no primeiro e terceiro semestres. Além disso, pode-se analisar que a maioria dos respondentes é do sexo feminino e da faixa etária dos 16 aos 20 anos, em vista disto, impacta nos resultados, visto que a predominância do estilo de aprendizagem será no sexo feminino. Nesse sentido, para determinar os estilos de aprendizagem predominantes nos alunos do curso de Ciências Contábeis, inicialmente analisou-se os índices de aprendizagem.

O Inventário de Estilo de Aprendizagem de Kolb (1984) proporciona a avaliação de quatro índices de aprendizagem que fazem parte do ciclo: Experiência Concreta (EC), Observação Reflexiva (OR), Conceituação Abstrata (CA) e Experimentação Ativa (EA).

A Conceituação Abstrata (CA) e Experiência Concreta (EC) podem ser utilizadas pelos alunos por meio da aplicação de métodos, que facilitem o seu aprendizado. Segundo Lima (2007, p. 33) "a captação ou percepção é entendida como a interpretação dos diversos estímulos registrados no cérebro pelos dispositivos sensoriais". Deste modo, conforme explana a teoria de Kolb, os índices são agrupados de dois em dois, em um plano cartesiano. Assim, inicialmente são avaliados os dois primeiros índices, Conceituação Abstrata e Experiência Concreta, conforme se apresenta na Tabela 2.

Tabela 2- Predominância na captação ou percepção da experiência

\begin{tabular}{l|c|c}
\hline & Frequência absoluta & Frequência relativa (\%) \\
\hline Conceituação Abstrata & 29 & $54,29 \%$ \\
\hline Experiência Concreta & 24 & $45,71 \%$ \\
\hline
\end{tabular}

Fonte: dados da pesquisa.

Percebe-se que não há uma predominância de um dos dois índices, visto que aproximadamente $54 \%$ dos alunos apreendem por meio da conceituação abstrata. Conforme Leite, Batista, Paulo e Siqueira (2008 p. 4) estes indivíduos "aprendem melhor quando são orientados por uma autoridade de modo impessoal, com ênfase teórica e análise sistemática.". Os demais alunos $45,71 \%$ aprendem por meio da experiência concreta. Segundo Cerqueira (2000, p. 4) estes estudantes aprendem melhor "com resultados de experiência específica". Nesse sentido, pode-se inferir que os alunos pertencentes a amostragem da pesquisa aprendem melhor quando a abordagem é abstrata, do que quando é concreta, embora a diferença entre os índices não seja alta.

Conforme a Tabela 3 pode-se analisar os dois últimos índices de aprendizagem quanto a predominância da Observação Reflexiva e a Experimentação Ativa.

Tabela 3- Predominância na transformação da experiência

\begin{tabular}{l|c|c}
\hline & Frequência absoluta & Frequência relativa (\%) \\
\hline Observação Reflexiva & 28 & $54,29 \%$ \\
\hline Experimentação Ativa & 25 & $45,71 \%$ \\
\hline
\end{tabular}

R. Cont. Ufba, Salvador-Ba, v. 9, n. 3, p. 118 - 134, set-dez 2015 
Fonte: dados da pesquisa.

Da mesma forma que a tabela anterior, pode-se observar na Tabela 3 que não há uma alta predominância quanto à Observação Reflexiva e a Experimentação Ativa, visto que a os percentuais foram de 54,29\% e 45,71\% respectivamente, significando uma distância de 8,58 pontos percentuais, com isso demonstra-se que os alunos da pesquisa aprendem melhor assistindo aulas do que fazendo tarefas em casa.

Após obter os resultados de predominância dos índices captação ou percepção da experiência e transformação da experiência, foi realizada a composição dos mesmos, diminuindo-se a Conceituação Abstrata pela Experiência Concreta (CA-CE) e Experimentação Ativa pela Observação Reflexiva (EA-OR). Deste modo, com a função dos dois eixos, colocaram-se os valores obtidos no plano cartesiano de Kolb e assim foi alcançado o estilo de aprendizagem preferido pelos alunos da pesquisa. Leite, Batista, Paulo e Siqueira (2008, p. 5) aduzem que o estilo de aprendizagem predominante dos alunos será determinado pelo "quadrante no qual a interseção das retas, que passam pelos pontos marcados nos eixos, estiver". Deste modo, são apresentados na tabela 4 os estilos de aprendizagem predominante nos alunos do curso de Ciências Contábeis da instituição investigada.

Tabela 4- Predominância dos estilos de aprendizagem

\begin{tabular}{c|c|c}
\hline Estilo de Aprendizagem & Frequência absoluta & Frequência relativa (\%) \\
\hline Divergente & 33 & $62,26 \%$ \\
\hline Assimilador & 12 & $22,64 \%$ \\
\hline Acomodador & 5 & $9,44 \%$ \\
\hline Convergente & 3 & $5,66 \%$ \\
\hline
\end{tabular}

Fonte: dados da pesquisa.

Em relação a Tabela 4, verifica-se que a predominância entre todos os semestres do curso de Ciências Contábeis é o estilo de aprendizagem divergente. Este resultado vem ao encontro do resultado obtido no estudo de Leite, Batista, Paulo e Siqueira (2008) nos quais os autores verificaram a predominância de estilo de aprendizagem dos estudantes do curso de Ciências Contábeis, obtendo como resultado a predominância do estilo divergente. Nesse sentido, os estudantes da pesquisa aprendem melhor por meio dos seus próprios pensamentos e sentimentos e com isso formulam suas próprias opiniões, e processam suas informações pela experiência.

Segundo Williams, Brown e Etherington (2013, p. 111) "divergentes preferem a observação à ação e operam bem em atividades de brainstorm". Acrescenta D'Amore, James e Mitchell (2012, p. 507) "divergentes tem uma imaginação forte, estão cientes de significados e valores, e tem uma boa capacidade de gerar ideias e visualizar situações concretas a partir de diferentes perspectivas".

A segunda preferência entre os alunos com uma variância ampla em relação ao primeiro estilo, foi o assimilador, este estilo é dominante nos indivíduos que entendem uma ampla gama de informações de forma resumida e lógica. Conforme Kolb (1984), os indivíduos do estilo assimilador são aqueles que organizam as informações, estabelecem modelos conceituais, testam suas ideias e analisam os dados quantitativos. Por fim, tem-se o estilo acomodador, que são os indivíduos que aprendem por tentativa e erro, seguido pelo convergente, que são os alunos que aprendem por meio de suas próprias descobertas.

A partir dos dados levantados sobre o estilo predominante dos alunos de todos os semestres, procede-se ao comparativo dos estilos de aprendizagem entre os sexos, faixas etárias e semestres.

R. Cont. Ufba, Salvador-Ba, v. 9, n. 3, p. 118 - 134, set-dez 2015 
O comparativo entre os estilos de aprendizagem segundo o sexo dos estudantes é apresentado na Tabela 5.

Tabela 5- Comparativo dos estilos de aprendizagem por sexo

\begin{tabular}{c|c|c|c|c}
\hline Estilo & $\begin{array}{c}\text { Frequência Absoluta } \\
(\%) \\
\text { Alunos do sexo } \\
\text { Feminino }\end{array}$ & $\begin{array}{c}\text { Frequência } \\
\text { relativa (\%) }\end{array}$ & $\begin{array}{c}\text { Frequência Absoluta } \\
(\%) \\
\text { Alunos do Sexo } \\
\text { Masculino }\end{array}$ & $\begin{array}{c}\text { Frequência } \\
\text { relativa (\%) }\end{array}$ \\
\hline Divergente & 23 & $63,89 \%$ & 10 & $58,82 \%$ \\
\hline Assimilador & 7 & $19,44 \%$ & 5 & $29,47 \%$ \\
\hline Acomodador & 3 & $8,33 \%$ & 2 & $11,76 \%$ \\
\hline Convergente & 2 & $5,56 \%$ & 1 & $5,88 \%$ \\
\hline
\end{tabular}

Fonte: dados da pesquisa.

Conforme a Tabela 5, observa-se que o estilo divergente em relação ao total de alunos do sexo feminino e do sexo masculino mais uma vez se mostrou predominante, porém percebe-se que o estilo assimilador, acomodador e convergente é dominante no sexo masculino. Pode-se concluir que embora o estilo de aprendizagem preferido pelos estudantes seja o divergente, o sexo masculino demonstra mais características dos outros estilos como o assimilador, acomodador e convergente. Evidencia-se, uma maior tendência nos homens do que em relação às mulheres em aprender de forma lógica (assimilador), com tentativas de erro (convergente), e por meio da experiência prática (acomodador). Em contrapartida como a maioria dos respondentes da amostra da pesquisa é do sexo feminino, a predominância do estilo de aprendizagem nesta pesquisa encontra-se neste gênero, demonstrando que estes alunos aprendem melhor pela reflexão (divergente) do que pela lógica e prática, pois tendem a analisar as consequências e impactos de suas decisões possivelmente ocasionadas por fatores éticos, culturais e familiares.

Isto se confirma com o estudo de Fox e Bartoholomae (1999) que identificaram que os estudantes do sexo masculino tendem a se adaptar-se com mais frequência ao estilo de aprendizagem convergente e acomodador.

A Tabela 6 evidencia, o comparativo dos estilos de aprendizagem por faixa etária de idade.

Tabela 6- Comparativo dos estilos de aprendizagem por faixa etária de idades

\begin{tabular}{c|c|c|c|c|c|c}
\hline & \multicolumn{6}{|c}{ Faixa Etária } \\
\hline Estilo & $\begin{array}{c}\text { Frequência } \\
\text { Absoluta (\%) } \\
\mathbf{1 6} \text { a0s 20 }\end{array}$ & $\begin{array}{c}\text { Frequência } \\
\text { relativa (\%) }\end{array}$ & $\begin{array}{c}\text { Frequência } \\
\text { Absoluta (\%) } \\
\mathbf{2 1} \text { aos 23 }\end{array}$ & $\begin{array}{c}\text { Frequência } \\
\text { relativa (\%) }\end{array}$ & $\begin{array}{c}\text { Frequência } \\
\text { Absoluta (\%) } \\
\mathbf{2 4} \text { aos 52 }\end{array}$ & $\begin{array}{c}\text { Frequência } \\
\text { relativa (\%) }\end{array}$ \\
\hline Divergente & 19 & $61,29 \%$ & 10 & $76,92 \%$ & 4 & $44,44 \%$ \\
\hline Assimilador & 9 & $29,03 \%$ & 1 & $7,69 \%$ & 2 & $22,22 \%$ \\
\hline Acomodador & 1 & $3,23 \%$ & 1 & $7,69 \%$ & 3 & $33,33 \%$ \\
\hline Convergente & 2 & $6,45 \%$ & 1 & $7,69 \%$ & 0 & 0 \\
\hline
\end{tabular}

Fonte: dados da pesquisa.

De acordo com a Tabela 6, o estilo de aprendizagem divergente, na faixa etária dos 21 aos 23 anos, é mais ativo em relação às outras idades. Já o estilo assimilador, destaca-se como a segunda preferência predominante na faixa etária dos 16 aos 20 anos. O estilo acomodador apresenta-se como a segunda preferência na faixa etária dos 24 aos 52 anos, e ainda, o estilo convergente não se demonstrou interessante entre os estudantes desta idade, deste modo, os 
resultados indicam que os estudantes a partir desta faixa etária, exploram mais atividades práticas.

Estes achados corroboram com o estudo de Cerqueira (2000), pois demonstra que a preferência pelo estilo de aprendizagem acomodador aumenta no decorrer das faixas etárias. A autora comenta que à medida que os estudantes perdem características de observar e pensar, adquirem experiências concretas e ativas, ou seja, fazer e sentir.

Os resultados destas faixas etárias vão ao encontro dos achados da pesquisa de Joy e Kolb (2009), que avaliaram em seu estudo, a cultura, sexo, idade, nível de escolaridade dos alunos de diferentes países. Os resultados da pesquisa demostram que a predominância maior quanto à idade, é nos estilos de aprendizagem divergente e assimilador.

A Tabela 7, apresenta o comparativo dos estilos de aprendizagem por semestre.

Tabela 7- Comparativo dos estilos de aprendizagem por semestre

\begin{tabular}{|c|c|c|c|c|c|c|c|c|}
\hline \multirow{2}{*}{$\begin{array}{c}\text { Estilo } \\
\text { Semestre }\end{array}$} & \multicolumn{8}{|c|}{ Alunos } \\
\hline & $\begin{array}{c}\text { Frequência } \\
\text { Absoluta } \\
(\%) \\
1^{\circ} \text { Sem. }\end{array}$ & $\begin{array}{c}\text { Frequê } \\
\text { ncia } \\
\text { relativa } \\
(\%)\end{array}$ & $\begin{array}{c}\text { Frequên } \\
\text { cia } \\
\text { Absoluta } \\
(\%) \\
3^{\circ} \text { Sem. } \\
\end{array}$ & $\begin{array}{c}\text { Frequênci } \\
\text { a relativa } \\
(\%)\end{array}$ & $\begin{array}{c}\text { Frequência } \\
\text { Absoluta } \\
(\%) \\
5^{\circ} \text { Sem. }\end{array}$ & $\begin{array}{c}\text { Frequência } \\
\text { relativa } \\
(\%)\end{array}$ & $\begin{array}{c}\text { Frequê } \\
\text { ncia } \\
\text { Absolut } \\
\text { a }(\%) \\
7^{\circ} \text { Sem. } \\
\end{array}$ & 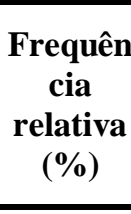 \\
\hline Divergente & 9 & $64,29 \%$ & 15 & $71,43 \%$ & 5 & $62,5 \%$ & 5 & $50 \%$ \\
\hline Assimilador & 5 & $35,71 \%$ & 2 & $9,52 \%$ & 2 & $25 \%$ & 2 & $20 \%$ \\
\hline Acomodador & 0 & 0 & 3 & $14,29 \%$ & 0 & 0 & 2 & $20 \%$ \\
\hline Convergente & 0 & 0 & 1 & $4,76 \%$ & 1 & 12,5 & 1 & $10 \%$ \\
\hline
\end{tabular}

Fonte: dados da pesquisa.

Em relação a Tabela 7, pode-se verificar que o estilo de aprendizagem divergente é predominante em todos os semestres. Uma das possíveis explicações para os alunos do primeiro semestre não terem se identificado com os estilos acomodador e convergente, pode ser o fato de que estes estilos exploram a experiência e alunos iniciantes tendem a aprender pelos estilos dos professores. Já no terceiro semestre, o estilo acomodador se destacou em relação ao assimilador. Deste modo, os alunos no decorrer dos semestres utilizam mais da experiência, dos sentimentos e pensamentos em seus estilos. Além disso, nos semestres finais, os alunos começam a utilizar em seus estilos de aprendizagem a prática (convergente), passando a identificar seus próprios estilos de aprendizagem.

O estudo de Reis, Paton e Nogueira (2012) é convergente a esses resultados, uma vez que para o perfil dos alunos de Ciências Contábeis, pode haver, pode haver uma tendência de que estudantes dos últimos semestres estejam exercendo atividades na área contábil, o que influencia nos resultados da pesquisa em relação aos estudantes ingressantes.

De mesmo modo, os resultados de Baldwin (1984) corroboram com os achados desta pesquisa, demonstrando que os alunos iniciantes aprendem pelos estilos dos professores e que no decorrer do curso passam a identificar seus próprios estilos de aprendizagem.

Por fim, os resultados deste estudo demonstram que o estilo de aprendizagem predominante do curso de Ciências Contábeis da UCEFF Faculdades, no município de Chapecó/CS, foi o divergente. Estes resultados também se verificam em relação à faixa etária, sexo e semestre pesquisados.

\section{CONSIDERAÇÕES FINAIS}

R. Cont. Ufba, Salvador-Ba, v. 9, n. 3, p. 118 - 134, set-dez 2015 
Este trabalho teve por objetivo analisar os estilos de aprendizagem dos alunos matriculados no curso de Ciências Contábeis da UCEFF Faculdades, no município de Chapecó/ SC. Para atingir-se o objetivo proposto, realizou-se uma pesquisa descritiva, com abordagem qualitativa, por meio de levantamento de dados com a aplicação do questionário. De um total de 150 alunos matriculados no curso de Ciências Contábeis da instituição investigada, obteve-se uma amostra de 53 alunos respondentes.

Por meio da revisão da literatura pode-se observar que o tema estilos de aprendizagem está evoluindo em diversas áreas e em diferentes contextos. Assim, o estudo buscou analisar as preferências dos estilos de aprendizagem dos alunos de Ciências Contábeis, almejando contribuir com o ensino superior, bem como, com a literatura da área.

Frente ao exposto, observar o cenário educacional e identificar o estilo de aprendizagem dos estudantes, torna-se relevante para o desenvolvimento das suas próprias estratégias de aprendizagem, e ainda, para auxiliar os docentes na observação e identificação da melhor forma de ensinar os alunos. Isso se confirma na pesquisa de Valente, Abib e Kusnik (2009) que averiguaram os estilos de aprendizagem dos professores e alunos do curso de Ciências Contábeis da Universidade de Ponta Grossa.

O Inventário de Estilos de Aprendizagem de Kolb tem sofrido algumas críticas e modificações, como o estudo de Manolis, Burns, Assudani e Chinta (2013) que modificou o Inventário de Estilo de Aprendizagem de Kolb de 1984, com o objetivo de torná-lo mais eficaz em identificar o estilo de aprendizagem dos indivíduos, mais econômico e com praticidade em sua de utilização.

Como contribuição relevante, os resultados da presente pesquisa, constatam que o estilo de aprendizagem predominante nos estudantes do curso de Ciências Contábeis da UCEFF Faculdades foi o divergente, ou seja, os alunos observados captam as informações por meio da experiência concreta, expressam seus sentimentos enquanto aprendem e interagem com o professor, bem como, com seus colegas. Estes resultados também se verificam em relação à faixa etária, sexo e semestre observados. Todavia, salienta-se que ocorreram algumas variações dentre os demais estilos de aprendizagem, em relação às faixas etárias e os semestres investigados.

Neste sentido, os estudantes a partir de certa faixa etária, qual seja, 24 aos 52 anos, exploram mais atividades práticas, em vista disso, à medida que os estudantes perdem características de observar e pensar, adquirem experiências concretas e ativas, ou seja, fazer e sentir. Assim, os alunos no decorrer dos semestres utilizam mais da experiência, dos sentimentos e pensamentos em seus estilos, sendo que. Nos semestres finais começam a apresentar estilos de aprendizagem voltados a prática, passando a identificar seus próprios estilos de aprendizagem.

Em relação ao gênero, devido à maioria dos respondentes da amostra da pesquisa ser do sexo feminino, a predominância do estilo de aprendizagem nesta pesquisa encontra-se neste gênero, demonstrando que a aprendizagem torna-se melhor pela reflexão do que pela lógica e prática, pois estes alunos tendem a analisar as consequências e impactos de suas decisões possivelmente ocasionadas por fatores éticos, culturais, familiares.

A limitação deste estudo consiste na impossibilidade da generalização dos resultados, tendo em vista a composição de sua amostragem. A utilização de um meio eletrônico restringiu a quantidade dos dados, limitando o alcance da pesquisa. Outra limitação destacada dá-se quanto à maioria dos respondentes da amostra da pesquisa pertencer ao sexo feminino, contudo tais limitações não comprometem os resultados encontrados.

Para pesquisas futuras, recomenda-se a avaliação dos estilos de aprendizagem dos alunos de Ciências Contábeis, em diferentes instituições de ensino do estado de Santa 
Catarina, realizando-se um comparativo com instituições de outros estados, com o intuito de se verificar possíveis diferenças nos estilos de aprendizagem em áreas geográficas distintas.

\section{REFERÊNCIAS}

ALLESSANDRINI, C. D, WEINBERG, C., GOUVEIA, D. da C, RUBINSTEIN. E, NEGREIROS. M.L.de M., KUPFER, M.C, CAMPOS, M.C. R.M. MOOJEN, S. Psicopedagogia: Uma prática, diferentes estilos. 1. ed. São Paulo: Casa do Psicólogo, 1999.

BALDWIN, B. A. RECKERS, P. MJ. Exploring the role of learning style research in accounting education policy. Journal of Accounting Education, v. 2, n. 2, p. 63-76, 1984.

BARDIN L. Análise de conteúdo. Ed. 70, Lisboa, 1977.

BRASIL. Lei $n^{\circ}$ 9.394. Estabelece as diretrizes e bases da educação nacional. 1996. Disponível em: http: <www.planalto.gov.br/ccivil_03/leis/19394.htm>. Acesso em: 20. mai., 2014.

CERQUEIRA, T. C. S. Estilos de aprendizagem em universitários. Tese (Doutorado em Educação) - Programa de Pós- Graduação em Educação, Universidade Estadual de Campinas. São Paulo, 2000.

D'AMORE, A., JAMES, S., MITCHELL, E. KL. Learning styles of first-year undergraduate nursing and midwifery students: A cross-sectional survey utilising the Kolb Learning Style Inventory. Nurse education today, v. 32, n. 5, p. 506-515, 2012.

FELDER, R. M., SILVERMAN, L. K. Learning and teaching styles in engineering education. Engineering education, v. 78, n. 7, p. 674-681, 1988.

FELDER, Richard M., SPURLIN, J. Applications, reliability and validity of the index of learning styles. International journal of engineering education, v. 21, n. 1, p. 103-112, 2005.

FIGUEIREDO, R. S., NORONHA, C. M. S., NETO, O. J. de O. Estilos de aprendizagem no ensino técnico agropecuário das escolas técnicas federais do Estado de Goiás. Revista Brasileira de Gestão e Desenvolvimento Regional, v. 4, n. 2, 2008.

FOX, J., BARTHOLOMAE, S. Student learning style and educational outcomes: evidence from a family financial management course. Financial Services Review, v. 8, n. 4, 1999.

GIL, A. C. Como elaborar projetos de pesquisa. 4. ed. São Paulo: Atlas, 2002.

JOY, S.; KOLB, D. A. Are there cultural differences in learning style? International Journal of Intercultural Relations, v. 33, n. 1, p. 69-85, 2009.

LIMA, A. I. A. de O. Estilos de aprendizagem segundo os postulados de David Kolb: uma experiência no curso de odontologia da UNOESTE. Dissertação (Mestrado em Educação) - Programa de Pós Graduação em Educação, Universidade do Oeste Paulista, Presidente Prudente, 2007. 
KERLINGER, F. N. Metodologia da pesquisa em ciências sociais: um tratamento conceitual. São Paulo: EPU, EDUSP, 1980.

KOLB, D. A. Experiential learning: Experience as the source of learning and development. Englewood Cliffs, NJ: Prentice-Hall, 1984.

LEITE FILHO, G. A., BATISTA, I.V.C., PAUlO, J.J. SIQUEIRA, R.L. Estilos de aprendizagem $\mathrm{x}$ desempenho acadêmico-uma aplicação do teste de Kolb em acadêmicos no curso de ciências contábeis. In: Congresso USP de Controladoria e Contabilidade, 2008.

MANOLIS, C. BURNS, D. J., ASSUDANI.R, CHINTA.R. Assessing experiential learning styles: A methodological reconstruction and validation of the Kolb Learning Style Inventory. Learning and Individual Differences, v. 23, p. 44-52, 2013.

METALLIDOU, P., PLATSIDOU, M. Kolb's Learning Style Inventory-1985: Validity issues and relations with metacognitive knowledge about problem-solving strategies. Learning and Individual Differences, v. 18, n. 1, p. 114-119, 2008.

OLIVEIRA, D. E. de. Impacto dos estilos de aprendizagem no desempenho acadêmico do ensino de contabilidade: uma análise dos estudantes da Universidade Federal do Rio Grande do Norte. Dissertação (Mestrado em Ciências Contábeis) - Programa Multiinstitucional e Inter-Regional de Pós- Graduação em Ciências Contábeis da Universidade de Brasília, Universidade Federal da Paraíba e Universidade Federal do Rio Grande do Norte, Natal, 2012.

PORTILHO, E. Como se aprende? Estratégias, estilo e metacognição. 2 ed. Rio de Janeiro: Wak Ed, 2011.

REIS, L. G. dos, PATON, C., NOGUEIRA, D. R. Estilos de aprendizagem: uma análise dos alunos do curso de ciências contábeis pelo método Kolb. Enfoque: Reflexão Contábil, v. 31, n. 1, p. 53-66. 2012.

Richardson, R. J. Pesquisa social: métodos e técnicas. 3. ed. São Paulo: Atlas, 1999.

SANTOS, A. A. A. dos, MOGNON, J. F. Estilos de aprendizagem em estudantes universitários. Boletim de Psicologia, v. 60, n. 133, p. 229-241, 2010.

SILVA, D. M. da. O impacto dos estilos de aprendizagem no ensino de Contabilidade na FEA-RP/USP. Dissertação (Mestrado em Ciências Contábeis) - Departamento de Contabilidade da Universidade de São Paulo, 2006.

SIQUEIRA, A. M. de O., PRATES, L. H. F., PAUlA I., OLIVEIRA D. de. Estilos de aprendizagem e estratégias de ensino em engenharia. XL Congresso Brasileiro de Educação em Engenharia, 2012.

SOARES, E. Metodologia Científica: Lógica, epistemologia e normas. São Paulo: Atlas, 2003. 
STOUT, D. E., \& RUBLE, T. L. A reexamination of accounting student learning styles. Journal of Accounting Education, v. 9, n. 2, p. 341-354, 1991.

VALENTE, N. T. Z., ABIB, D. B., KUSNIK, L. F. Análise dos Estilos de Aprendizagem dos Alunos e Professores do Curso de Graduação em Ciências Contábeis de uma Universidade Pública do Estado do Paraná com a Aplicação do Inventário de David Kolb. Contabilidade Vista \& Revista, v. 18, n. 1, p. 51-74, 2009.

WILLIAMS, B., BROWN, T., ETHERINGTON, J. Learning style preferences of undergraduate pharmacy students. Currents in Pharmacy Teaching and Learning, v. 5, n. 2, p. 110-119, 2013. 